\title{
Simultaneous Temporal Progress of Sorghum Anthracnose and Leaf Blight in Crop Mixtures with Disparate Patterns
}

\author{
H. K. Ngugi, S. B. King, J. Holt, and A. M. Julian
}

First author: Department of Plant Pathology, University of Georgia, Athens 30602; second author: 1448 Hampton Circle, Goshen, IN 46526; and third and fourth authors: Natural Resources Institute, University of Greenwich, Central Avenue, Chatham Maritime, Kent ME4 4TB, U.K.

Accepted for publication 8 May 2001.

\section{ABSTRACT}

Ngugi, H. K., King, S. B., Holt, J., and Julian, A. M. 2001. Simultaneous temporal progress of sorghum anthracnose and leaf blight in crop mixtures with disparate patterns. Phytopathology 91:720-729.

Field studies were conducted at Alupe in western Kenya in 1995 and 1996 to evaluate the efficacy of crop and species mixtures for the management of sorghum anthracnose (caused by Colletotrichum sublineolum) and leaf blight (caused by Exserohilum turcicum). The progress of these diseases developing simultaneously on a susceptible sorghum cultivar planted in inter- or intra-row mixtures of varying proportions with either maize or resistant sorghum was monitored. The effects of host type and mixture patterns on disease progress were compared by parameter estimates derived from fitted Lotka-Volterra competition equations and nonlinear logistic models. Competition coefficients were not significant and their confidence intervals included zero in most cases, suggesting that interactions between $C$. sublineolum and E. turcicum did not occur. Mixtures of the susceptible sorghum with either the nonhost maize or the resistant sorghum delayed the time when disease is first observed and reduced the rate of disease progress and carrying capacity for both anthracnose and leaf blight, with a more pronounced effect on the latter disease. The lower efficacy of mixtures in reducing anthracnose was attributed to an aggregated spatial pattern, coupled with higher rates of progress for this disease. Intra-row mixtures were more efficient than inter-row mixtures in reducing disease development in all years. The implications of these observations for the management of sorghum diseases under smallscale farming systems are discussed.

Additional keywords: Colletotrichum graminicola, competition, Sorghum bicolor.
The concomitant occurrence or association of pathogen species may significantly affect the temporal attributes of the component species $(30,31,50)$. The nature of the resulting interactions may vary depending upon both biotic and abiotic factors (30). On one extreme, pathogen species with similar ecological requirements, such as leaf wetness or age at which the host is susceptible, may interact negatively if they compete for resources such as healthy host tissue. In such a case, one of the pathogens may inhibit the growth of the other through antibiosis, or the pathogen species may mitigate competition effects at the expense of growth and reproduction. Negative interactions can also occur if the presence of one pathogen triggers host responses that affect the other organism, resulting in cross-protection (14) through acquired systemic resistance $(47,51)$. Alternatively, pathogen interactions may be synergistic, for example, where host defense responses are overcome through simultaneous infections, allowing both or one of the pathogen species to develop more rapidly $(42,44)$. What ever the nature of the interaction, the result will affect the intrinsic rates of population growth of the individual pathogen species and the resulting disease intensity $(2,5,41,44)$.

Although several statistical procedures are available for analyzing disease progress where multiple pathogens occur on the same host $(2,24,31,33)$, reports of such studies are limited $(24,33,50)$. This is a paradox because in nature the occurrence of more than one disease in the field is more common $(5,15,42,52)$. Madden et al. (24) illustrated the use of Lotka-Volterra competition equations to analyze the temporal progress of two virus diseases in a tobacco field, but found no evidence for a significant interaction in the

Corresponding author: H. K. Ngugi; E-mail address: hngugi@yahoo.com

Publication no. P-2001-0621-02R

(C) 2001 The American Phytopathological Society incidence of the two viruses. Nevertheless, the authors cautioned against the use of separate regression models to describe the dynamics of the two viruses, arguing that correlated error terms associated with simultaneous estimation of disease incidences would result in biased parameter estimates. Weber (52) observed that epidemics of Stagonospora nodorum which, when analyzed with a single disease progress model indicated a severity below the control threshold, exceeded such a threshold when the presence of Erysiphe graminis was considered in a model linking the two diseases, thus illustrating the limitations of separate models to analyze simultaneous disease progress.

Studies on disease interactions in the tropics are few in spite of the existence of many foliar disease complexes in these regions. Sorghum (Sorghum bicolor (L.) Moench), a major cereal crop in tropical Africa (9), is affected by anthracnose (Colletotrichum sublineolum P. Henn. Kabat et Bub. Syn. = C. graminicola Wilson) and leaf blight (Exserohilum turcicum Pass. Leonard and Suggs.), both of which occur in the same agroecological zones and often infect susceptible cultivars concomitantly, particularly in the wet humid zones of eastern Africa $(34,35)$. Both anthracnose and leaf blight are considered the most destructive diseases of improved, high-yielding sorghum cultivars in this region $(8,12$, 16,35). Effective disease management strategies that target these diseases simultaneously are required if sorghum grain yields, currently estimated at $<1 \mathrm{t} / \mathrm{ha}$ in the three east African countries of Kenya, Uganda, and Tanzania (13), are to be improved. Knowledge on how the concomitant occurrence of $C$. sublineolum and E. turcicum affects disease progress in the field can greatly facilitate the development of sound disease management practices. Although the simultaneous occurrence of these diseases in eastern Africa has been reported previously $(8,12,16,34)$, no attempt has been made to assess the nature of this association and how it might affect disease progress and yield loss. 
Host resistance is the most economical way to manage sorghum leaf diseases, including anthracnose and leaf blight $(11,39)$. However, breeding for resistance to multiple pathogens takes time and, in most cases, sources of resistance are effective against only one or a few pathogen species $(32,37,53,54)$. Breeding programs always have to select for resistance to both pathogens simultaneously. Characteristic symptoms are easily identifiable, and sources of resistance to both have been identified (International Crops Research Institute for the Semi-Arid Tropics, unpublished data), but the widespread deployment of resistant cultivars is limited because they often possess unsuitable characteristics in taste, color, milling quality, and low yields. In addition, even when cultivars with suitable characteristics are bred, there is always the potential for new pathogen races emerging that can overcome host resistance $(53,54)$. This is especially likely for pathogens with high levels of variability such as E. turcicum (17) and $C$. sublineolum $(6,40)$. Alternative means of disease management such as use of cultivar and species mixtures and other cultural practices are, therefore, recommended to complement host resistance and reduce selection pressure $(11,34,39)$. Mixtures not only extend the options in deployment of host resistance $(3,27,53-$ $55)$, they also result in yield stability and improve food security in subsistence agriculture $(23,48)$. Although both inter- and intraspecies mixtures incorporating sorghum are commonly observed in eastern Africa $(18,34)$, no information is available on the potential of these mixtures for the management of sorghum diseases.

The first objective of this study was to compare the efficacy of different mixtures for managing sorghum anthracnose and leaf blight and determine whether the parameters describing disease progress were affected by crop mixtures or spatial arrangement patterns. Because preliminary experiments in 1994 revealed that these diseases generally occurred concomitantly on the same host plant, the second objective was to determine whether interactions between the two causal agents could be detected by statistical analysis of disease progress curves.

\section{MATERIALS AND METHODS}

Plant material. Maize and sorghum were selected for this study primarily because they are commonly intercropped in western Kenya and northern Uganda. An improved commercially available sorghum cultivar, KARI Mtama 1, susceptible to both $C$. sublineolum and E. turcicum, was intercropped in mixtures of different proportions and arrangements with either sorghum cv. IS 8193 (improved land race cultivar from western Kenya with good resistance to both $C$. sublineolum and E. turcicum) or maize cv. HB 511 (1995) or cv. KCB (1996). The main consideration in selecting the sorghum cultivars for this study was the level of resistance to both $C$. sublineolum and E. turcicum. Other considerations included similarity in maturity and yield and easily identifiable characteristics such as grain color (red and white) and plant pigment (red and tan) in response to injury. Both maize cultivars are nonhost to $C$. sublineolum and to E. turcicum strains that attack sorghum.

Mixtures. Three experiments were carried out in fields with a history of disease at the Kenya Agricultural Research Institute (KARI) Alupe substation. Planting for the long rains (lr) seasons was on 9 March 1995 and 23 March 1996. The treatments consisted of susceptible sorghum cv. KARI Mtama 1 intercropped with resistant sorghum cv. IS 8193 (sorghum mixtures), or maize (maize mixtures) in the ratios of 1:0, 3:1, 1:1, 1:3, and 0:1 planted either as inter-row or intra-row mixtures (Fig. 1). Treatments were arranged in a randomized complete block design replicated three times. Individual plots consisted of $104-\mathrm{m}$ rows, and the outer two were planted with maize in all treatments to minimize interplot interference. The 1996 short rains (sr) experiment was planted 16 August 1996. In this experiment, the resistant sorghum treatments that were less effective in the previous two seasons were removed to allow use of more replications (five instead of three) and larger plots. Plots in the 1996sr experiment consisted of 12 rows each $(5 \mathrm{~m}$ long), with the outer two rows in each plot planted with maize. Instead of the recommended $60 \mathrm{~cm}$ between row spacing for sorghum, a compromise spacing of $75 \mathrm{~cm}$ was adopted in all experiments to allow suitable agronomic conditions for intercropping with maize. Standard crop management procedures for growing sorghum were followed in all seasons.

Data collection. All experiments relied on natural inoculum for disease development. Plants were assessed at 5- to 8-day intervals from crop booting stage to crop maturity, and data for the two sorghum cultivars were recorded separately. At each assessment date, at least 10 plants of each sorghum cultivar were sampled for disease severity in each plot. The severity of each disease was estimated by the percentage of area affected on the top five leaves of each plant as described in Ngugi et al. (35). For each disease, there were eight assessments in 1995 and nine in each of the 1996 experiments. However, data for the first assessment in the 1996 experiments were omitted because neither of the diseases was detected.

Statistical analyses. We have shown previously (35) that separate epidemics of both leaf blight and anthracnose at this location can be adequately summarized with logistic models. When two diseases occur together, the Lotka-Volterra competition equations can be used to analyze disease progress (24). Let anthracnose severity $=y_{1}$ and leaf blight severity $=y_{2}$, and the parameters followed by subscript 1 refer to anthracnose and those followed by 2 refer to leaf blight. The rate of anthracnose and for leaf blight progress when these diseases develop simultaneously is given by a set of linked logistic equations:

$$
\begin{aligned}
& d y_{1} / d t=r_{1} y_{1}\left(1-y_{1}-a_{21} y_{2}\right) \\
& d y_{2} / d t=r_{2} y_{2}\left(1-y_{2}-a_{12} y_{1}\right)
\end{aligned}
$$

The parameters $a_{21}$ and $a_{12}$ assess the competition effects of leaf blight on anthracnose and vice versa. One of the assumptions implicit in these equations is that individually these diseases are capable of causing $100 \%$ leaf area damage. Because neither of these diseases causes $100 \%$ severity at this location (35), equation 1 was expanded as in Madden et al. (24):

$$
\begin{aligned}
& d y_{1} / d t=r_{1} y_{1}\left(K_{1}-y_{1}-a_{21} y_{2}\right) / K_{1} \\
& d y_{2} / d t=r_{2} y_{2}\left(K_{2}-y_{2}-a_{12} y_{1}\right) / K_{2}
\end{aligned}
$$

where $K_{1}$ and $K_{2}$ are the carrying capacity (maximum severity) for anthracnose and leaf blight, respectively. For each treatment, equation 2 was fitted as described below to mean disease severity values obtained by averaging data from the 10 plants sampled in each plot at each assessment date for the 1995lr and 1996sr data sets. Anthracnose failed to develop in the 19961r experiment, in spite of severe epidemics occurring in fields adjacent to the experimental plots. Thus, the equation describing leaf blight progress during the 1996lr season can be reduced to a simple logistic model.

In order to test one of the mechanisms underlying mixture efficacy, a nonlinear logistic model $\left(y_{i}=K / 1+\exp \left[-r\left(t_{i}-\mu\right)\right]+\varepsilon_{i}\right)$ was also fitted to separate data sets for each disease once it was established that interaction coefficients were not significant. For each plot, an estimate of time taken for disease severity to reach $2 \%\left(t_{2}\right)$ was derived from this equation by setting $y=2$ and solving for $t: t_{2}=\{-\log [(K / 2)-1] / r\}+\mu$. This parameter provides an estimate of the time at which disease could be first observed (35). Unlike the delay parameter of Lannou et al. (21), which estimates the durability of mixture effects, $t_{2}$ indicates the efficiency of mixtures in delaying detectable disease onset.

Computational details. Models were fitted with Model Maker version 3 (Cherwell Scientific, Oxford, U.K.) using Simplex algorithm with weighted least squares to estimate parameters and to calculate confidence intervals as well as correlation and covari- 
ance matrices. The first nonzero disease severity for each plot was specified as the initial value of disease $\left(y_{0}\right)$. It was considered inappropriate to estimate this value as an additional parameter because the number of observations imposed a limitation on the number of parameters that could be estimated. Initial values for the rate, $r$, and competition coefficients $a_{12}$ and $a_{21}$ were specified as 0.1 , whereas the highest disease severity obtained for a particular disease in each plot was specified as the initial $K$ value for that disease. Model fit was assessed by a series of criteria including coefficient of determination $\left(R^{2}\right)$, asymptotic standard error of parameter estimates (10), and plots of fitted and observed values. Confidence intervals were used to determine which parameters were estimated with highest precision; those with intervals including zero were considered poor estimates. An absolute rate parameter was computed by multiplying $K$ and $r$ values to help compare epidemics with different carrying capacities. The effects of mixtures on parameter estimates were assessed by analysis of variance, and regression analysis was used to test for differences between mixture proportions. Tukey-Kramer family errors were used in tests of a priori set hypotheses at $P \leq 0.05$ to reduce the likelihood of type I errors. Statistical comparison of means was carried out using GENSTAT 5 release 3.2 (Rothamsted Experimental Station, Harpenden, UK).

\section{RESULTS}

Competition models. Leaf blight and anthracnose severity on resistant cv. IS 8193 was low, often not exceeding 5\%. Therefore, emphasis on statistical analysis was placed on susceptible cv. KARI Mtama 1. The Lotka-Volterra competition equations provided an excellent description of disease progress data for both anthracnose and leaf blight in the 19951r and 1996sr seasons. The regression model accounted for $>93 \%$ of the variation in all epidemics; this proportion was at least $97 \%$ in more than half of
Treatment 1

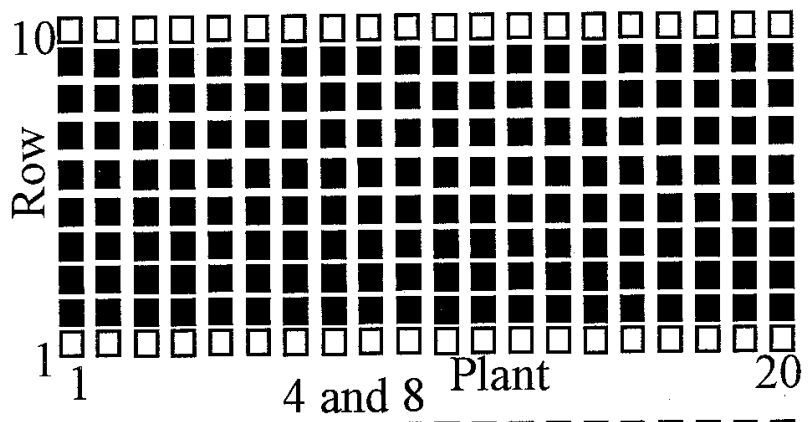

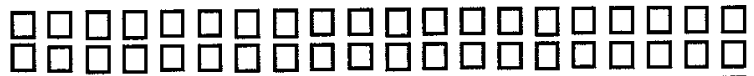

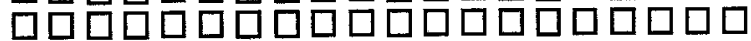

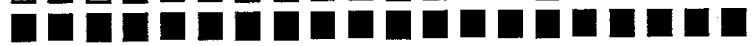

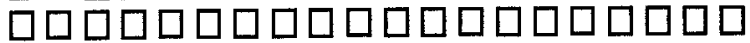

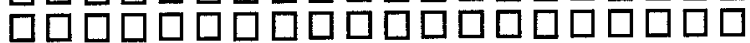

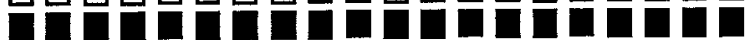

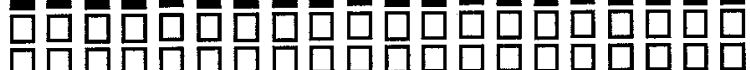

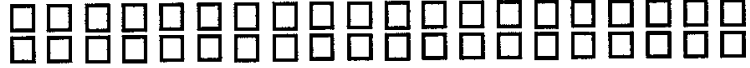
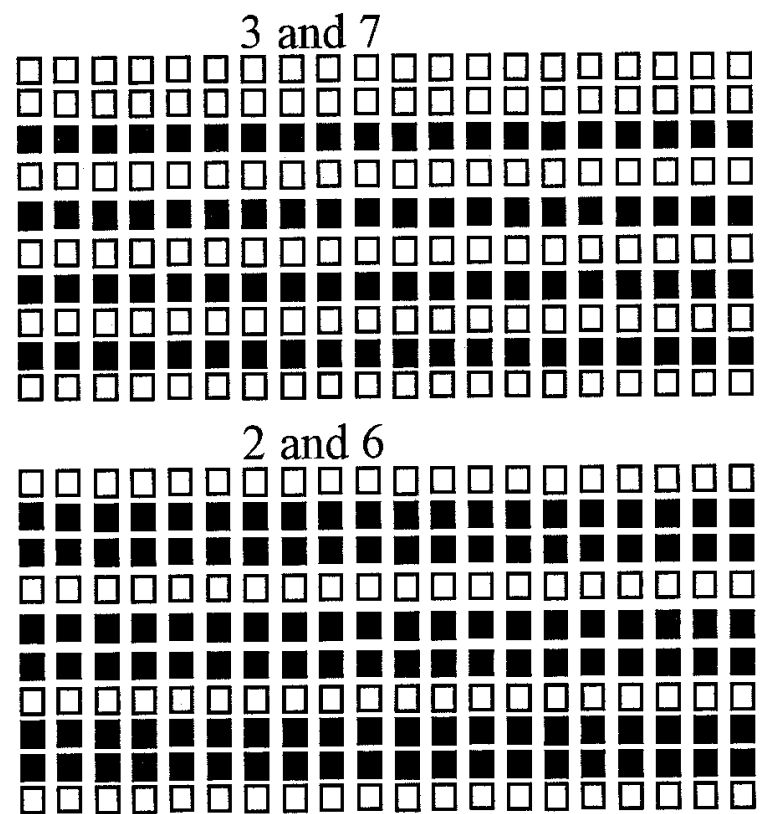

5 and 9

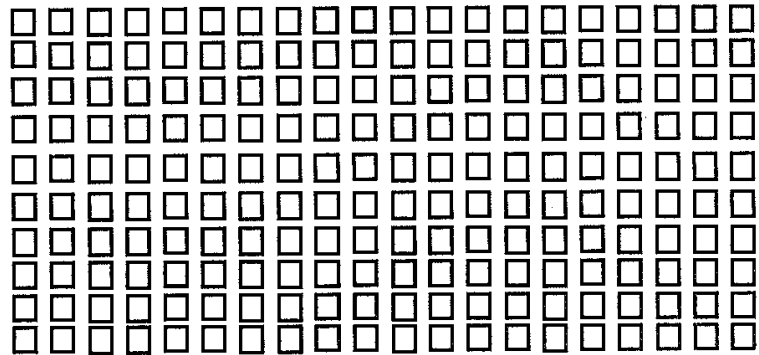

15 and 12

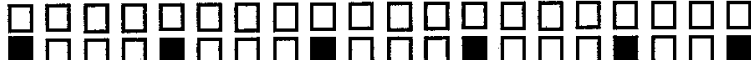

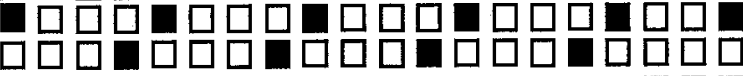
-

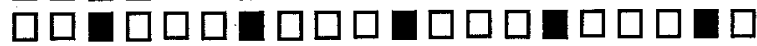

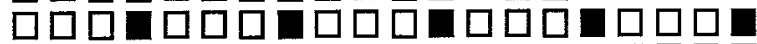

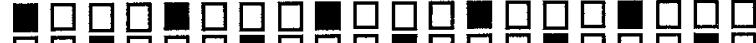

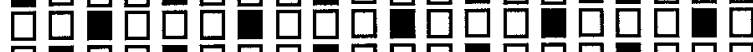

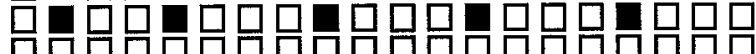
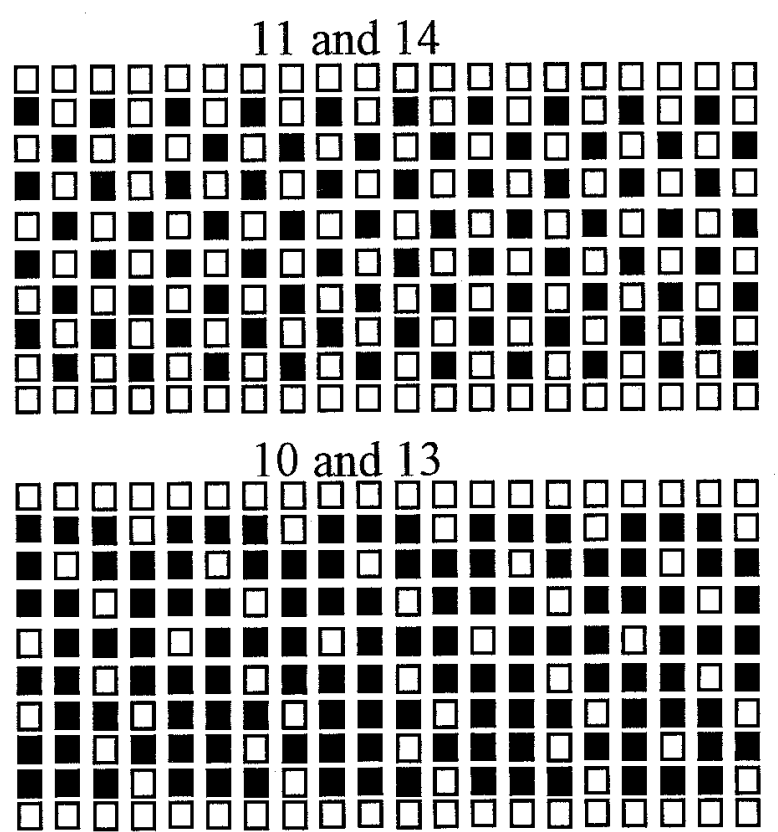

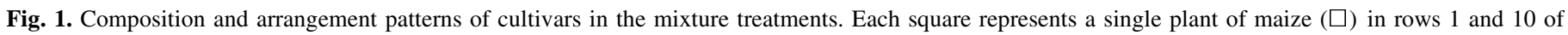

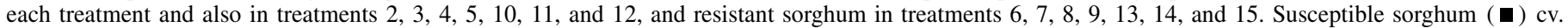
KARI Mtama 1 in all treatments. Treatments were replicated three times in a randomized complete block design. Only one block is shown. 
the epidemics analyzed (Tables 1 and 2). In addition, mean square errors were low compared with the mean squares for the model (Tables 1 and 2). Plots of fitted models closely resembled the observed data in all cases (Figs. 2 to 4). Only curves for 1995lr and 1996sr seasons are shown but those for the 1996lr season were equally well described by the simple logistic model (Table 3 ).

Of the six parameters estimated for each pair of disease progress curves, the competition coefficients $a_{12}$ and $a_{21}$ were the least precisely estimated, followed by the carrying capacity for leaf blight $\left(K_{2}\right)$. In $>80 \%$ of the cases, the confidence intervals for both $a_{12}$ and $a_{21}$ included zero (data not shown). The rate parameters $\left(r_{1}\right.$ and $\left.r_{2}\right)$ were estimated with highest precision, often exceeding their asymptotic standard deviations by 2 orders of magnitude. Thus, the highest level of confidence should be placed in the rate parameters. In all cases, $K_{1}$ and $K_{2}$ were estimated less precisely than $r_{1}$ and $r_{2}$.

In the two seasons that the two diseases occurred together (1995lr and 1996sr), the absolute rates $\left(r_{1} K_{1}\right)$ of anthracnose progress were higher than those for leaf blight in any given treatment (Tables 1 and 2), but this was not unexpected because anthracnose always had higher carrying capacities $\left(K_{1}\right)$ (Figs. 2 to 4). Neither of the two diseases had a significant competition effect

TABLE 1. Parameter estimates and model fit statistics for simultaneous progress of Colletotrichum sublineolum and Exserohilum turcicum on susceptible sorghum (SS) cv. KARI Mtama 1, planted at different proportions and arrangement patterns, in mixtures with maize (M) or resistant sorghum (RS) cv. IS 8193 at Alupe, western Kenya during the 1995 long rains season

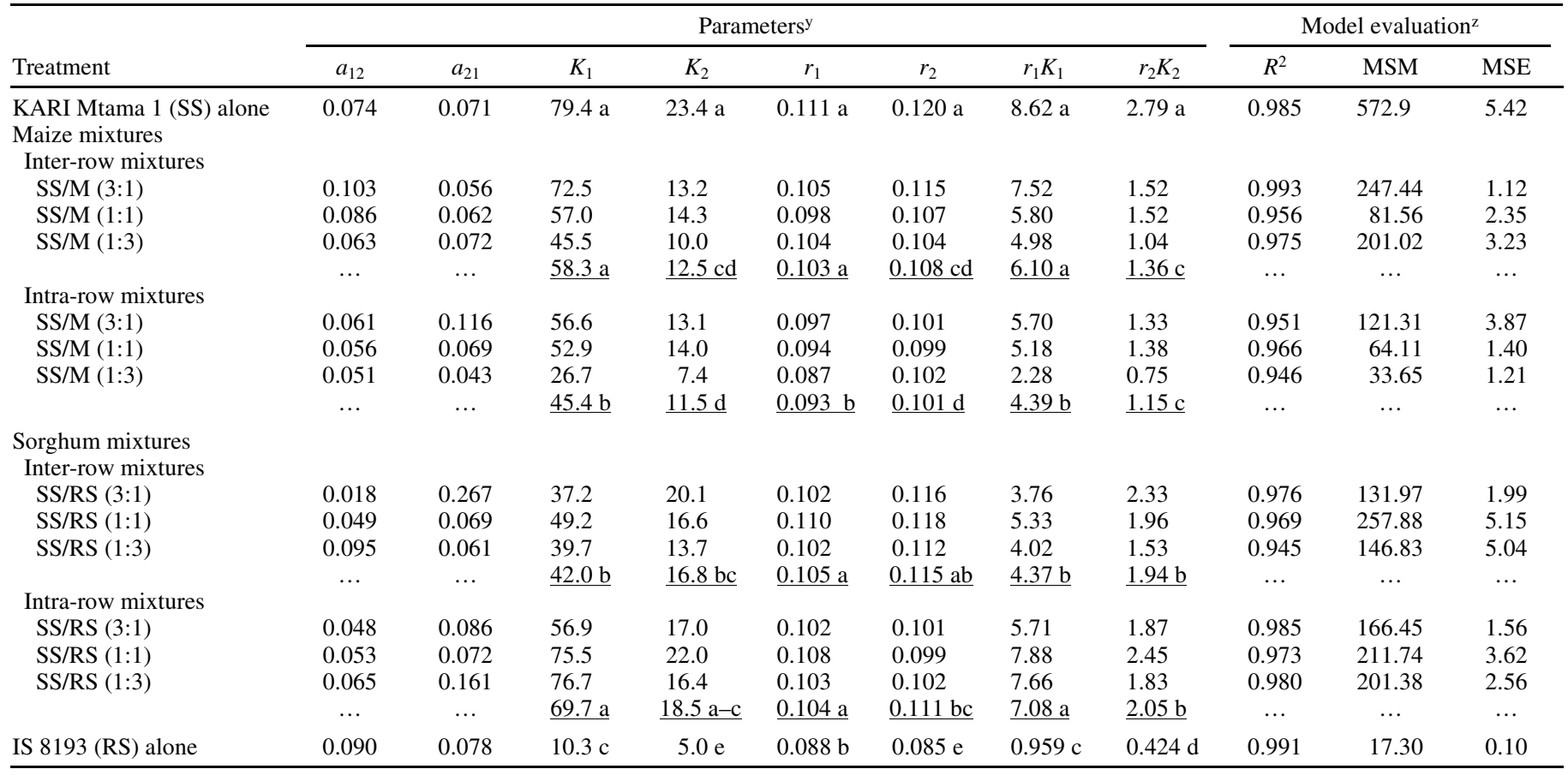

y Values underlined are means of three mixture proportion treatments within each arrangement pattern group; those within a column followed by same letter are not different at $P<0.05$ based on Tukey-Kramer procedure. $a_{12}$ and $a_{21}$ are competition coefficients, $r_{1}=$ rate of anthracnose progress, $r_{2}=$ rate of leaf blight progress; $K_{1}=$ anthracnose carrying capacity, $K_{2}=$ leaf blight carrying capacity; $r_{1} K_{1}$ and $r_{2} K_{2}$ a generalization of Richards absolute rate of anthracnose and leaf blight progress, respectively.

${ }^{\mathrm{z}} \mathrm{MSM}=$ mean sum of square model; MSE $=$ mean sum of square error of agreement between the model and the data. Fitted model: $d y_{1} / d t=r_{1} y_{1}\left(K_{1}-y_{1}-\right.$ $\left.a_{21} y_{2}\right) / K_{1}$ and $d y_{2} / d t=r_{2} y_{2}\left(K_{2}-y_{2}-a_{12} y_{1}\right) / K_{2}$.

TABLE 2. Parameter estimates and model fit statistics of anthracnose (Colletotrichum sublineolum) and leaf blight (Exserohilum turcicum) progress on susceptible sorghum (SS) cv. KARI Mtama 1 grown in inter- or intra-row mixtures with maize (M) at Alupe, western Kenya during the 1996 short rains season

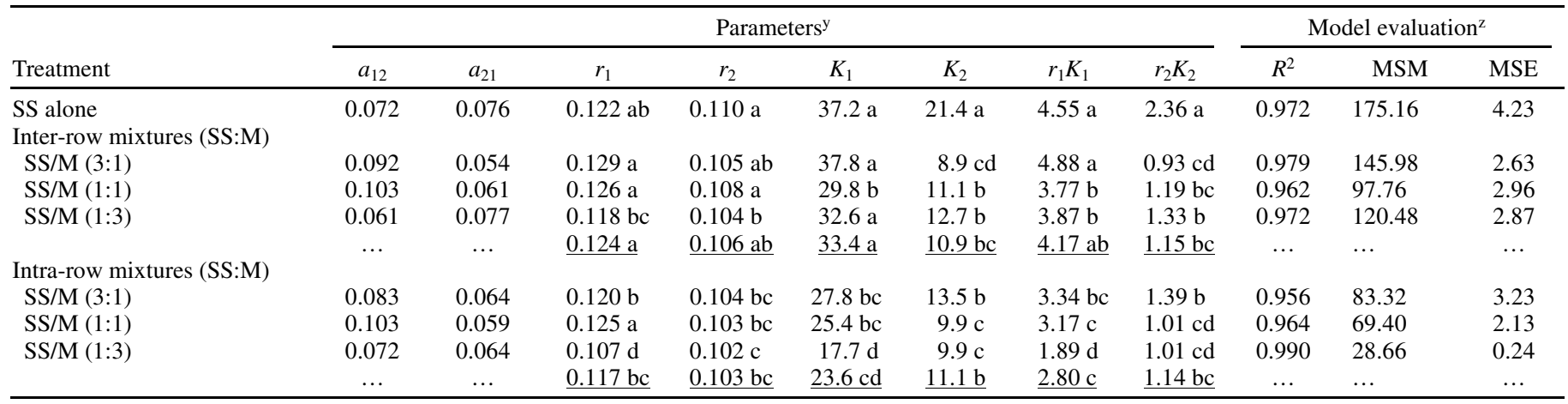

y Values underlined are means of three mixture proportion treatments within each arrangement pattern group; those within a column followed by same letter are not different at $P<0.05$ based on Tukey-Kramer procedure. $a_{12}$ and $a_{21}$ are competition coefficients, $r_{1}=$ rate of anthracnose progress, $r_{2}=$ rate of leaf blight progress; $K_{1}=$ anthracnose carrying capacity, $K_{2}=$ leaf blight carrying capacity; $r_{1} K_{1}$ and $r_{2} K_{2}$ a generalization of Richards absolute rate of anthracnose and leaf blight progress, respectively.

z $\mathrm{MSM}=$ mean sum of square model; MSE $=$ mean sum of square error of agreement between the model and the data. Fitted model: $d y_{1} / d t=r_{1} y_{1}\left(K_{1}-y_{1}-\right.$ $\left.a_{21} y_{2}\right) / K_{1}$ and $d y_{2} / d t=r_{2} y_{2}\left(K_{2}-y_{2}-a_{12} y_{1}\right) / K_{2}$. 
on the other (Tables 1 and 2). Mean estimates of competition coefficients $a_{12}$ and $a_{21}(0.065$ and 0.0815 for $19951 \mathrm{r}$ and 0.083 and 0.064 for $1996 \mathrm{sr})$ were not different $(P>0.1)$ from each other in either year. Both competition parameters were unaffected $(P>$
0.1 ) by mixture treatments (proportion of constituents and arrangement patterns) in both years (Tables 1 and 2). The estimates of $a_{12}$ and $a_{21}$ from resistant cv. IS 8193 (values not shown) were not different from those of susceptible cv. KARI Mtama 1.

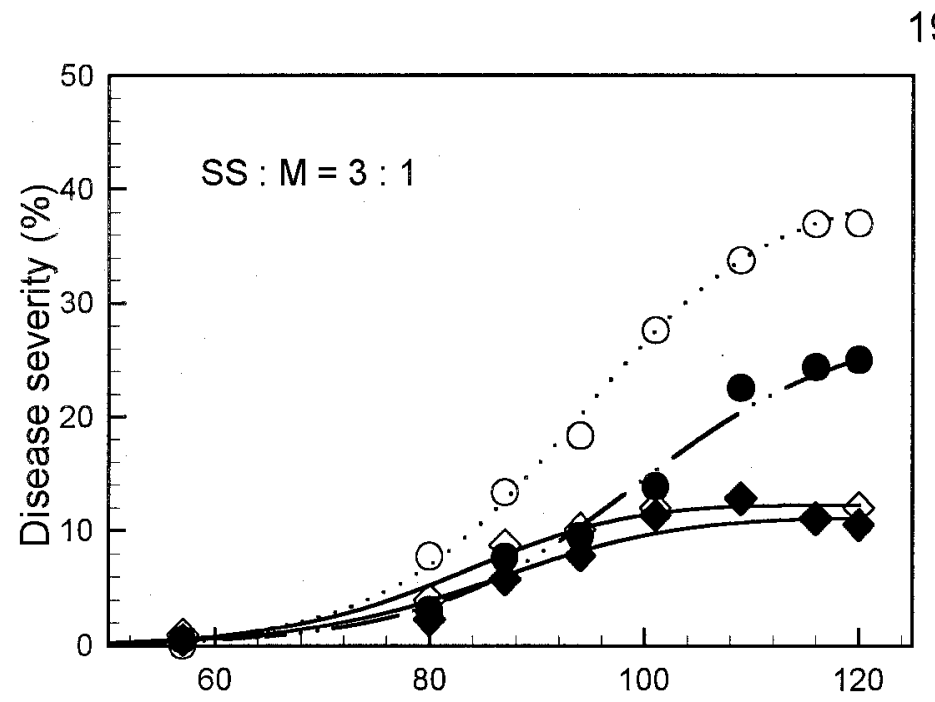

$1995 \mathrm{Ir}$
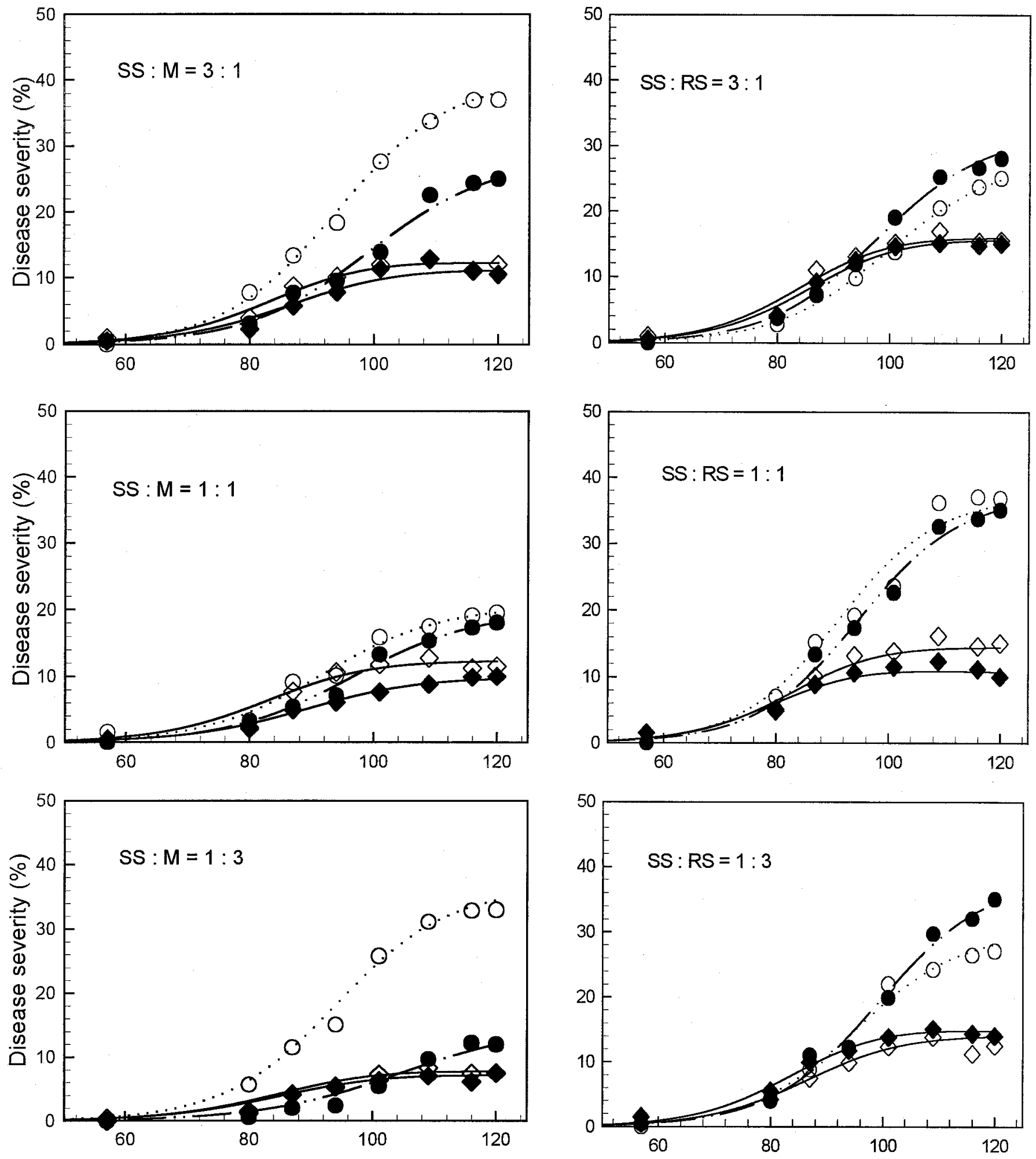

Time after crop emergence (days)

Fig. 2. Disease progress curves for anthracnose and leaf blight on susceptible sorghum cv. KARI Mtama 1 growing in mixtures with either maize or resistant sorghum during the 1995 long rains season. The symbols represent observed values $(\bigcirc, \bullet$ anthracnose, and $\diamond$, leaf blight, with open symbols indicating interrow mixtures and closed symbols indicating intra-row mixtures). Lines are the fitted values of the Lotka-Volterra competition equations for each treatment. SS $=$ susceptible sorghum; $\mathrm{M}$ = maize; and RS = resistant sorghum. 
Mixture effects on anthracnose. There were variable results for the effects of mixtures on anthracnose progress between the years. In both years, parameter estimates for anthracnose progress were affected more by the spatial arrangements (inter- versus intra-row) and by the type of resistant crop used (maize versus sorghum) than by the proportions of constituent mixtures (Tables 1 to 3 ). The estimated time when anthracnose was first observed $\left(t_{2}\right)$ was delayed in intra-row mixtures, but inter-row mixtures did not affect this parameter in either year (Table 4). For all mixtures as a group, the mean estimate of the carrying capacity for anthracnose $\left(K_{1}\right)$ was not statistically different $(P>0.1)$ from that of the sole susceptible sorghum plots in 1995. However, maize intra-row mixtures and sorghum inter-row mixtures significantly $(P<0.01)$ reduced this measure of final disease severity (Table 1$)$. In the 1996sr experiment, inter-row mixtures as a group did not affect anthracnose carrying capacity, but the maize intra-row mixtures reduced $K_{1}$ by $36.6 \%$ of the mean for control plots (Table 2 ), with the efficacy of mixtures increasing with decreasing proportion of sorghum in the mixtures (Fig. 4). Mean rates of anthracnose progress were between 0.111 for the sole susceptible sorghum plot compared with 0.093 for maize intra-row mixtures in 1995, a $16.4 \%$ reduction (Table 1). Mean absolute rates of progress were 4.39 and 2.80 in intra-row mixtures compared with 8.26 and 4.55 for the sole susceptible plot in 1995 and 1996, respectively (Tables 1 and 2). Similar to the carrying capacity, the rates were not affected by the proportion of the resistant crop within the different mixture patterns.
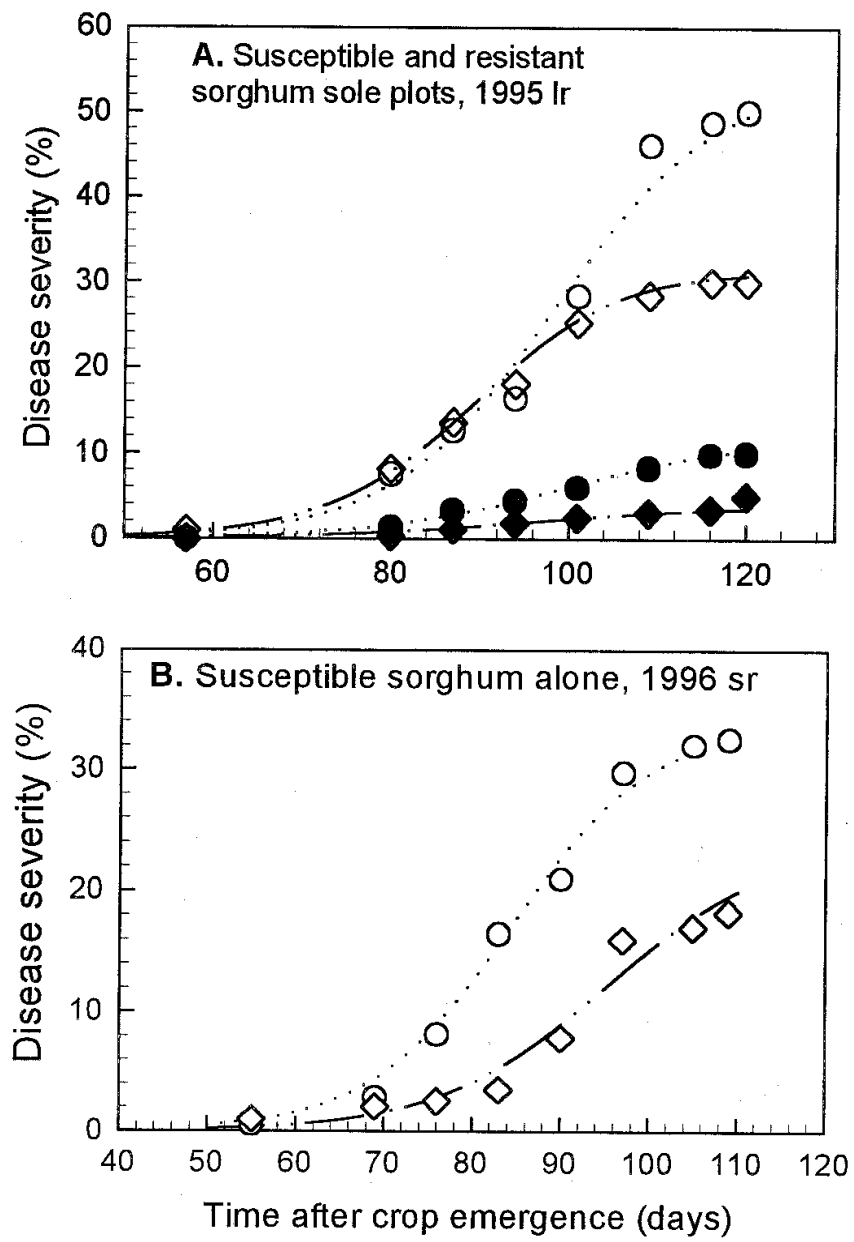

Fig. 3. Disease progress curves for anthracnose $(O, \bullet)$ and leaf blight $(\diamond, \bullet)$ developing simultaneously in sole plots of $\mathbf{A}$, susceptible and resistant sorghum cultivars (open and closed symbols, respectively) during the 1995 long rains season, and $\mathbf{B}$, susceptible sorghum during the 1996 short rains season. Symbols represent observed values, whereas lines are fitted values from the Lotka-Volterra competition equations.
Mixture effects on leaf blight. As with anthracnose, leaf blight progress was affected more by the spatial arrangement and by the type of resistant crop used than by the proportion of the components in the mixtures. Mixtures reduced leaf blight carrying capacity $(P<0.01)$ on the susceptible sorghum cultivar in all three seasons, and intra-row mixtures were generally more effective than inter-row mixtures. Maize intra-row mixtures reduced $K_{2}$ by
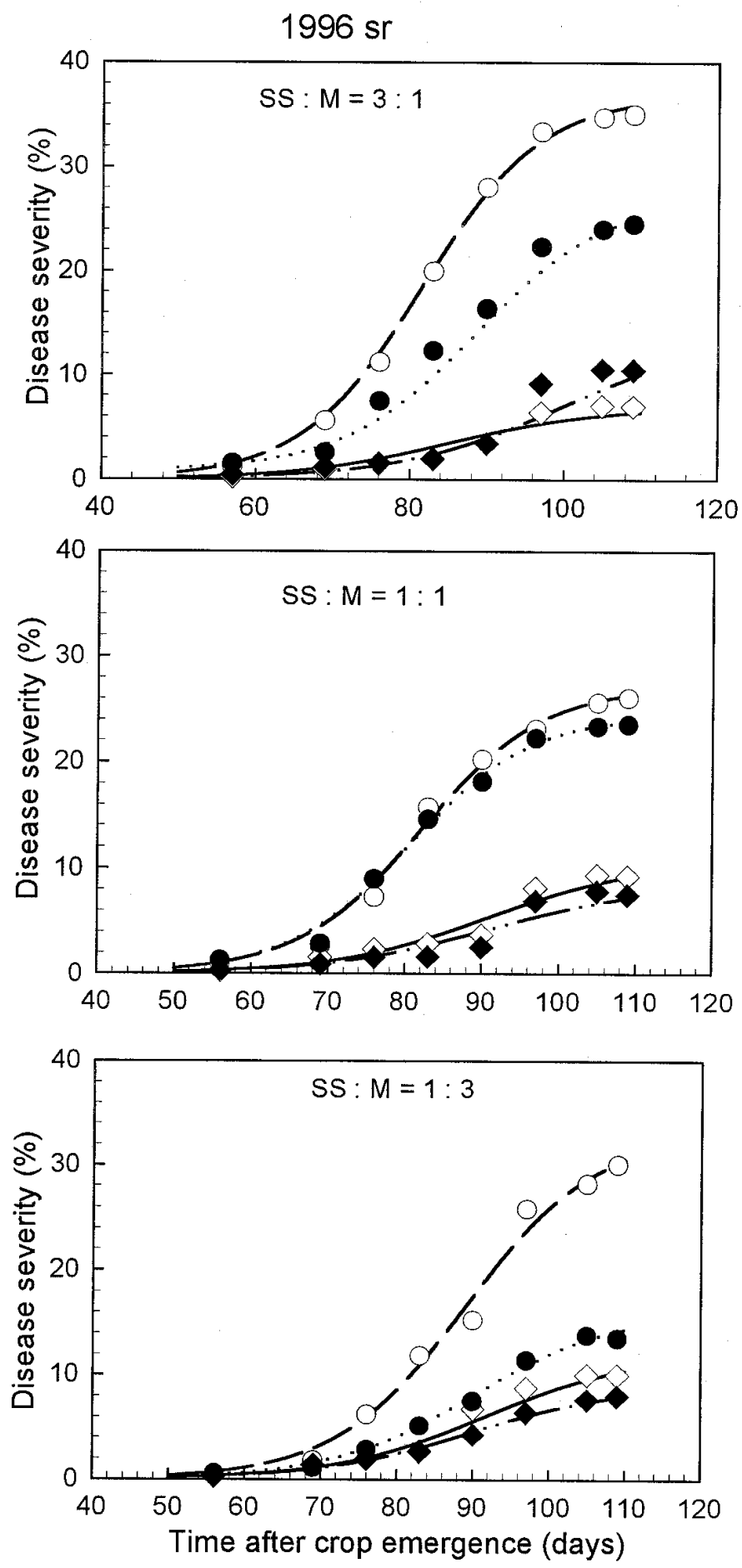

Fig. 4. Disease progress curves for anthracnose and leaf blight on susceptible sorghum cv. KARI Mtama 1, growing in mixtures with maize at Alupe in western Kenya, during the 1996 short rains season. Symbols represent observed values $(\mathrm{O}, \bullet$ anthracnose, and $\downarrow$, leaf blight, in inter- and intrarow mixtures, respectively). Lines are the fitted values of the Lotka-Volterra competition equations for each treatment. SS = susceptible sorghum; and $\mathrm{M}=$ maize. 
$50.9 \%$ of the mean of control plots compared with $46.6 \%$ for inter-row mixtures in 1995 , and by $81.3 \%$ compared with $79.9 \%$ in the 19961r experiment (Table 1). However, this trend was not repeated in the 1996sr experiment when the inter-row mixtures generally matched the intra-row mixtures (Table 2). Excepting a ratio of 3:1 for both susceptible sorghum/maize inter-row and intra-row treatments, the carrying capacities of mixture proportion treatments were not different from one another or from their averages in the 1996sr (Table 2). No differences were observed in $K_{2}$ among the various proportions in either of the $1 \mathrm{r}$ seasons (Tables 1 and 3). In all three seasons, the susceptible sorghum grown in mixtures with maize had reduced leaf blight carrying capacity $\left(K_{2}\right)$ compared with plots in which it was mixed with the resistant sorghum cultivar, irrespective of the proportions and arrangement patterns of the mixtures (Tables 1 to 3 ). In all three seasons, the absolute rates of leaf blight progress were only affected by the type of resistant crop used, but not by either the cropping patterns or the mixture proportions (Tables 1 to 3 ). Maize-based mixtures were more efficient than resistant sorghumbased mixtures in delaying time when leaf blight was first observed in the field (Table 4). Intra-row mixtures generally delayed $t_{2}$ more than inter-row mixtures, but the differences between these arrangements were only significant for the 1996sr experiment, probably because the means were estimated more precisely for this data set (five instead of three replicates) (Table 4).

\section{DISCUSSION}

Despite earlier reports indicating that anthracnose and leaf blight occur concomitantly on the same sorghum host cultivar $(8,9,12,16,34)$, the effects of this association on disease progress was not investigated in detail. The progress of the two diseases in the same plot of sorghum has been described previously using separate logistic models and interactions tested by correlation analysis based on disease severity data from a single observation in time (35). Although this previous study revealed no significant correlation between the two pathogens, the use of correlation analysis failed to take into account the effects that possible interactions might have had on disease progress. In the present study, we modeled the progress of anthracnose and leaf blight epidemics occurring simultaneously on a susceptible sorghum cultivar using Lotka-Volterra competition equations. Such an analysis is prudent because correlated error terms associated with estimating the two diseases can lead to biased parameters estimates (24). More importantly, however, interactions that cannot be revealed by separate models, could significantly alter the course of epidemic progress. This would significantly alter the epidemic dynamics and the implications for management strategies based upon such results (52).

Competition coefficients in the linked equations were not statistically significant, implying that competition or synergism did not occur between the two diseases. This was surprising because the two diseases affect the same type of host tissue, and may suggest that the Lotka-Volterra competition equations do not apply very well to these epidemics, probably because the epidemics were limited by factors other than exhaustion of host tissues. Such factors may include onset of adult plant resistance to E. turcicum $(19,34,49)$, allowing severe anthracnose often associated with plant maturity $(34,35)$ to develop without competition. In any case, leaf blight severity in the present study was generally low, further reducing the likelihood of an interaction.

For both leaf blight and anthracnose, the effect of the mixtures was to delay the time when disease was first observed and lower the rate of disease progress and the carrying capacity on the susceptible sorghum. Both maize and sorghum mixtures had a more pronounced effect on E. turcicum progress than on $C$. sublineolum progress. These differences may best be explained by considering the mode of within-field dispersal of these pathogens in relation to the disease-meliorating mechanisms operating in crop mixtures. Within a host crop, E. turcicum is predominantly

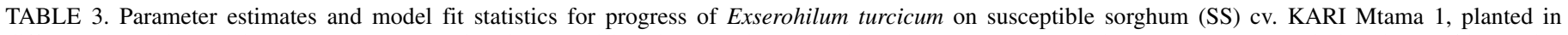

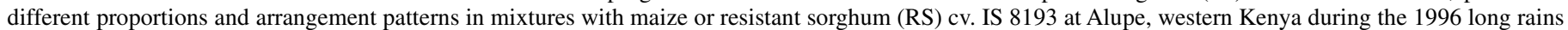
season

\begin{tabular}{|c|c|c|c|c|c|c|}
\hline \multirow[b]{2}{*}{ Treatment } & \multicolumn{3}{|c|}{ Parameters ${ }^{\mathrm{y}}$} & \multicolumn{3}{|c|}{ Model evaluation ${ }^{z}$} \\
\hline & $r_{2}$ & $K_{2}$ & $r_{2} K_{2}$ & $R^{2}$ & MSM & MSE \\
\hline KARI Mtama 1(SS) alone & $0.132 \mathrm{a}$ & $28.3 \mathrm{a}$ & $3.727 \mathrm{a}$ & 0.985 & 808.60 & 20.6 \\
\hline \multicolumn{7}{|l|}{ Maize mixtures } \\
\hline \multicolumn{7}{|l|}{ Inter-row mixtures } \\
\hline SS/Maize $(3: 1)$ & 0.116 & 6.5 & 0.760 & 0.993 & 247.44 & 0.92 \\
\hline SS/Maize (1:1) & 0.110 & 5.2 & 0.573 & 0.956 & 81.56 & 0.85 \\
\hline \multirow[t]{2}{*}{ SS/Maize (1:3) } & 0.104 & 5.4 & 0.568 & 0.975 & 201.02 & 0.6 \\
\hline & $\underline{0.110 \mathrm{~b}}$ & $\underline{5.7 \mathrm{c}}$ & $\underline{0.634 \mathrm{c}}$ & $\ldots$ & $\ldots$ & $\ldots$ \\
\hline \multicolumn{7}{|l|}{ Intra-row mixtures } \\
\hline SS/Maize (3:1) & 0.116 & 6.0 & 0.685 & 0.951 & 121.31 & 0.87 \\
\hline SS/Maize (1:1) & 0.112 & 4.7 & 0.537 & 0.966 & 64.11 & 1.27 \\
\hline \multirow[t]{2}{*}{ SS/Maize (1:3) } & 0.105 & 5.3 & 0.545 & 0.946 & 33.65 & 0.71 \\
\hline & $\underline{0.111 \mathrm{~b}}$ & $\underline{5.3 \mathrm{c}}$ & $\underline{0.589 \mathrm{c}}$ & $\ldots$ & $\ldots$ & $\ldots$ \\
\hline \multicolumn{7}{|l|}{ Sorghum mixtures } \\
\hline \multicolumn{7}{|l|}{ Inter-row mixtures } \\
\hline SS/RS (3:1) & 0.118 & 13.3 & 1.582 & 0.976 & 131.97 & 4.48 \\
\hline SS/RS (1:1) & 0.124 & 9.7 & 1.208 & 0.969 & 257.88 & 2.41 \\
\hline \multirow[t]{2}{*}{ SS/RS (1:3) } & 0.124 & 14.8 & 1.869 & 0.945 & 146.83 & 3.23 \\
\hline & $\underline{0.122 \mathrm{a}}$ & $\underline{12.7 \mathrm{~b}}$ & $\underline{1.553 \mathrm{~b}}$ & $\ldots$ & $\ldots$ & $\ldots$ \\
\hline \multicolumn{7}{|l|}{ Intra-row mixtures } \\
\hline SS/RS (3:1) & 0.118 & 11.3 & 1.357 & 0.985 & 166.45 & 1.93 \\
\hline SS/RS (1:1) & 0.128 & 13.6 & 1.712 & 0.973 & 211.74 & 4.37 \\
\hline \multirow[t]{2}{*}{ SS/RS (1:3) } & 0.122 & 11.7 & 1.415 & 0.980 & 201.38 & 2.99 \\
\hline & $\underline{0.122 \mathrm{a}}$ & $\underline{12.2 \mathrm{~b}}$ & $\underline{1.495 \mathrm{~b}}$ & $\ldots$ & $\ldots$ & $\ldots$ \\
\hline IS 8193 (RS) alone & $0.091 \mathrm{c}$ & $2.1 \mathrm{~d}$ & $0.187 \mathrm{~d}$ & 0.945 & 17.30 & 0.184 \\
\hline
\end{tabular}

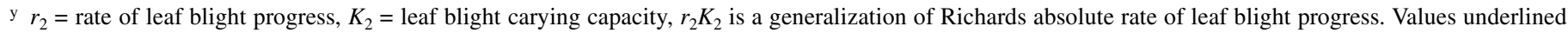

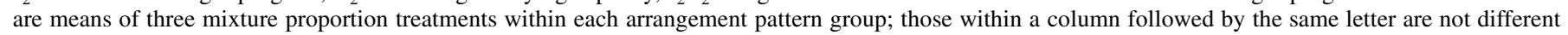
at $P<0.05$ based on Tukey-Kramer procedure.

${ }^{\mathrm{z}} \mathrm{MSM}=$ mean sum of square model, MSE $=$ mean sum of square error of agreement between the model and the data. Fitted model: $d y_{1} / d t=r_{2} y_{2}\left(K_{2}-y_{2}\right) / K_{2}$. 
wind-dispersed (26), with a relatively shallow dispersal gradient and uniformly distributed incidence. By contrast, $C$. sublineolum conidia are mainly splash-dispersed (36). Although no information is available on the spore dispersal gradients of $C$. sublineolum, splash-dispersed spores usually show steep gradients with distance away from the source (46).

Mixtures are thought to control diseases by physically impeding inoculum dispersal $(3,4,27,28,53)$, increasing the distance between susceptible hosts, diluting the number of susceptible genotypes, and by systemic induced resistance for diseases caused by complex pathogen races $(7,22,27)$. In turn, these factors reduce the amount of inoculum available to initiate secondary infections (4) or slow the rate of lesion expansion (21). Disease severity in a mixture component is, therefore, determined by the proportions of available inoculum leading to autoinfection (sensu Robinson) (43) or alloinfection $(1,28)$. The greater efficacy of mixtures for controlling E. turcicum could result from the shallow dispersal gradients and relatively lower rates of disease progress for this pathogen. In both field and computer simulation studies, the efficacy of mixtures in controlling diseases increases with decreasing rates of progress $(21,28,29)$ and decreasing steepness of spore dispersal gradients $(20,25)$.

By contrast, autoinfections from splash-borne spores landing on the initial host plants may have contributed more to $C$. sublineolum development. In such a case, mixtures would be less effective in controlling disease progression on the susceptible cultivar because autoinfection is, by definition, independent of the presence of other plants in the mixtures. Mixtures, therefore, cannot not provide effective control for diseases caused by pathogens that are primarily splash-dispersed $(7,28,53)$, at least not on a susceptible host within such mixtures, although Ntahimpera et al. (38) reported effective reduction of dry bean anthracnose caused by $C$. lindemuthianum. Although $C$. lindemuthianum is more closely related to $C$. sublineolum than the obligate pathogens for which disease progress in mixtures has been studied extensively, differences reported here may reflect those involved in the two pathosystems such as differences in the canopy structures of sorghum and bean. It is also worthy to note that Ntahimpera et al. (38) were unable to detect differences in the rate parameters of disease progress, and their reported reductions were based on means of both susceptible and resistant plants within mixture plots, opposed to the susceptible plants only as considered here.

Secondly, initial disease distribution and higher rates of progress may have affected mixture efficacy in controlling spread of C. sublineolum. Anthracnose epidemics were always more focal relative to those of leaf blight. Significant differences between replicates of the same treatment in the $r, K$, and $r K$ parameters for anthracnose indicate that variation in these disease progress metrics could be attributed more to plot location than to treatment effects. With steep deposition gradients, much of the infection in a focus occurs on the initial plants infected, a condition that limits the effectiveness of the mixtures (25). Another factor that may have reduced mixture efficacy on anthracnose is the relatively higher rates of lesion expansion for this disease toward crop maturity. In computer-simulated epidemics, Lannou et al. (21) reported that higher lesion growth rates reduce mixture efficacy for disease control.

The results presented indicate that mixing susceptible sorghum with either maize or resistant sorghum cultivar greatly reduced $E$. turcicum severity and had considerable effect on the development of $C$. sublineolum. To the best of our knowledge, the results of the mixture component including maize provide the first report on the use of species mixtures for the management of sorghum diseases. The results of mixtures containing a resistant sorghum component support the findings of Sifuentes-Barrera and Frederiksen (45), who reported reduced E. turcicum severity in mixtures of sorghum hybrids in Mexico. Data on anthracnose provide the first report on the use of mixtures for the management of sorghum anthracnose. These observations are important and might explain the low disease severity often observed in farmers' fields in eastern Africa. In this region, sorghum is grown as a mixture of landraces, often intercropped with a variety of other crops, including maize and cassava $(9,18,34)$.

Maize mixtures were relatively more efficient in reducing disease than sorghum mixtures. This observation is not surprising because resistant sorghum cv. IS 8193 was not immune to either E. turcicum or C. sublineolum. In the severe epidemics of the 1995 experiment, cv. IS 8193 developed as much as 10\% anthracnose severity in the sole plots. It is reasonable to assume that inoculum from this cultivar may have contributed to the higher disease recorded on susceptible cv. KARI Mtama 1 plants compared with mixtures involving maize for which no anthracnose or leaf blight symptoms were observed. However, differences between maize and the resistant sorghum in plant unit areas and canopy structure may also have contributed to these differences in efficacy.

The higher efficacy of intra-row mixtures compared with that of inter-row mixtures in reducing rates of disease progress can only be attributed to changes in genotype unit area. In inter-row arrangements, the susceptible host genotype unit area was always greater than that of the intra-row patterns for mixture treatments composed of a similar proportion of resistant or nonhost plants and susceptible sorghum cv. KARI Mtama 1. Increasing the host genotype area can greatly reduce the efficacy of mixtures in controlling disease development (27-29). This study, therefore, shows that in developing countries where farmers already extensively grow crops in mixtures, better management of sorghum anthracnose and leaf blight can be achieved by use of intra-row as opposed to inter-row cropping patterns. The absence of significant effects associated with differing proportions of susceptible and resistant genotypes indicates a wide range in the proportion of the cultivars/crops within which the mixtures were effective. This should allow farmers an element of flexibility on the amount of each cultivar or crop they could grow. In conclusion, we have provided evidence for absence of interaction between $C$. sublineolum

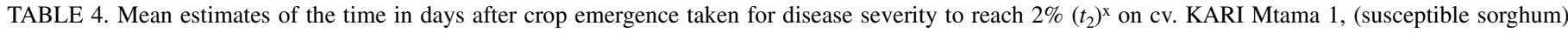
growing in mixtures with either maize or resistant sorghum cv. IS 8193 in three cropping seasons at Alupe, western Kenya

\begin{tabular}{|c|c|c|c|c|c|}
\hline \multirow[b]{2}{*}{ Treatment $^{\mathrm{y}}$} & \multicolumn{2}{|c|}{ Anthracnose ${ }^{z}$} & \multicolumn{3}{|c|}{ Leaf blight ${ }^{\mathrm{z}}$} \\
\hline & $19951 \mathrm{l}$ & $1996 s r$ & $19951 \mathrm{l}$ & 1996lr & $1996 s r$ \\
\hline Susceptible sorghum alone & $70.2 \mathrm{a}$ & $69.9 \mathrm{a}$ & $69.2 \mathrm{a}$ & $64.0 \mathrm{a}$ & $76.8 \mathrm{a}$ \\
\hline Maize/susceptible sorghum inter-row & $74.5 \mathrm{a}$ & $71.7 \mathrm{a}$ & $80.6 \mathrm{c}$ & $78.9 \mathrm{~b}$ & $78.9 \mathrm{a}$ \\
\hline Resistant sorghum/susceptible sorghum inter-row & $76.3 \mathrm{a}$ & $\ldots$ & $75.6 \mathrm{~b}$ & $67.4 \mathrm{a}$ & $\ldots$ \\
\hline Maize/susceptible sorghum intra-row & $84.2 \mathrm{~b}$ & $72.8 \mathrm{c}$ & $83.2 \mathrm{c}$ & $74.9 \mathrm{~b}$ & $81.7 \mathrm{~b}$ \\
\hline Resistant sorghum/susceptible sorghum intra-row & $80.8 \mathrm{~b}$ & $\ldots$ & $74.9 \mathrm{a}$ & $67.3 \mathrm{a}$ & $\ldots$ \\
\hline Resistant sorghum alone & $85.9 \mathrm{~b}$ & $\ldots$ & $101.5 \mathrm{~d}$ & $88.4 \mathrm{c}$ & $\ldots$ \\
\hline
\end{tabular}

$\mathrm{x} t_{2}$ is an estimate of time when disease could be first observed in the field and measures the effects of treatments on delaying disease onset.

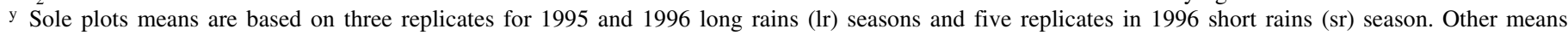
represent those of all the ratios.

z Values within a column followed by the same letter are not different at $P<0.05$ in contrasts based on Scheffé's procedure. 
and E. turcicum infecting the same sorghum plant, and showed that mixtures of susceptible sorghum with either maize or resistant sorghum can provide disease control for both anthracnose and leaf blight of sorghum.

\section{ACKNOWLEDGMENTS}

We thank H. Scherm and G. Hughes for a critical review of the manuscript and J. Were, E. Manyasa, A. Ilah, and H. Emojong for their technical support at Alupe. This paper is an output from a project jointly funded by the U.K. Department for International Development (DFID), and the International Crops Research Institute for the Semi-Arid Tropics (ICRISAT).

\section{LITERATURE CITED}

1. Barrett, J. A. 1980. Pathogen evolution in multiline and cultivar mixtures. Z. Pflanzenkr. Pflanzenschutz 87:383-396.

2. Barrett, J. A. 1983. Estimating relative fitness in plant parasites: Some general problems. Phytopathology 73:510-512.

3. Barrett, J. A., and Wolfe, M. S. 1980. Pathogen response to host resistance and its implication in breeding programs. EPPO Bull. 10:341-347.

4. Burdon, J. J. 1978. Mechanisms of disease control in heterogeneous plant populations-An ecologist's view. Pages 99-112 in: Plant Disease Epidemiology. P. R. Scott and A. Bainbridge, eds. Blackwell Scientific Publications, Oxford.

5. Campbell, C. L., and Madden, L. V. 1990. Introduction to Plant Disease Epidemiology. John Wiley \& Sons, New York.

6. Casela, R. C., Ferreira, A. S., and Zeller, K. A. 1995. Pathotype variation in the sorghum anthracnose fungus: A phylogenetic perspective for resistant breeding. Pages 257-276 in: Diseases Analysis Through Genetics and Biotechnology: Interdisciplinary Bridges to Improved Sorghum and Millet Crops. J. F. Leslie and R. A. Frederiksen, eds. Iowa State University Press, Ames.

7. Chin, K. M., and Wolfe, M. S. 1984. The spread of Erysiphe graminis hordei in mixtures and varieties. Plant Pathol. 33:89-100.

8. Doggett, H. 1980. Sorghum diseases in East Africa. Pages 33-35 in: Sorghum Diseases: A World Review. Proc. Int. Workshop Sorghum Dis. 1978. International Crops Research Institute for the Semi-Arid Tropics, Patancheru, India.

9. Doggett, H. 1988. Sorghums. 2nd ed. Longman, Harrow, U.K.

10. Draper, N. R., and Smith, H. 1981. Applied Regression Analysis. 2nd ed. John Wiley \& Sons, New York.

11. Duncan, R. R., and de Milliano, W. A. J. 1995. Plant disease control. Pages 35-74 in: Diseases Analysis Through Genetics and Biotechnology: Interdisciplinary Bridges to Improved Sorghum and Millet Crops. J. F. Leslie and R. A. Frederiksen, eds. Iowa State University Press, Ames.

12. Esele, J. P. E. 1995. Foliar and head diseases of sorghum. African Crop Sci. J. 3:185-189.

13. Food and Agriculture Organization of the United Nations. 1999. FAO Quarterly Bulletin of Statistics. FAO Vol. 12.

14. Fulton, R. W. 1986. Practices and precautions in the use of cross protection for plant virus disease control. Annu. Rev. Phytopathol. 24:76-81.

15. Garrett, K. A., and Mundt, C. C. 1999. Epidemiology in mixed host populations. Phytopathology 89:984-990.

16. Hulluka, M., and Esele, J. P. E. 1992. Sorghum diseases in eastern Africa. Pages 21-24 in: Sorghum and Millets Diseases: A Second World Review. W. J. A. de Milliano, R. A. Frederiksen, and G. D. Bergston, eds. International Crops Research Institute for the Semi-Arid Tropics, Patancheru, India.

17. Jama, A. N. 1995. Variability in Exserohilum turcicum (Pass.) Leonard and Suggs (= Setosphaeria turcica (Lutt.) Leonard and Suggs.) isolates from sorghum and maize in Africa. Ph.D. thesis. University of Reading, U.K.

18. Jameson, J. D. 1970. Agriculture in Uganda. Uganda Government Ministry of Agriculture and Forestry, Oxford University Press, London.

19. Julian, A. M., Crowson, H. L., and de Milliano, W. J. 1994. Factors influencing epidemiology of Exserohilum turcicum on sorghum. Afr. Crop Sci. Conf. Proc. 1:263-268.

20. Kiyosawa, S. 1976. A comparison by simulation of disease dispersal in pure and mixed stands of susceptible and resistant plants. Jpn. J. Breed. 26:137-145.

21. Lannou, C., De Vallavieille-Pope, C., and Goyeau, H. 1994. Host mixture efficacy in disease control: Effects of lesion growth analyzed through computer-simulated epidemics. Plant Pathol. 43:651-662.

22. Lannou, C., De Vallavieille-Pope, C., and Goyeau, H. 1995. Induced resistance in host mixtures and its effect on disease control in computersimulated epidemics. Plant Pathol. 44:478-489.
23. Lénné, J. M., Teverson, D. M., and Jeger, M. J. 1994. Evaluation of plant pathogens in complex ecosystems. Pages 63-77 in: Ecology of Plant Pathogens. J. P. Blakeman and B. Williamson, eds. CAB International, Wallingford, U.K.

24. Madden, L. V., Pirone, T. P., and Raccah, B. 1987. Temporal analysis of two viruses increasing in the same tobacco fields. Phytopathology 77: 974-980.

25. McCartney, H. A., and Fitt, B. D. L. 1987. Spore dispersal gradients and disease development. Pages 109-118 in: Populations of Plant Pathogens: Their Dynamics and Genetics. M. S. Wolfe and C. E. Catten, eds. Blackwell Scientific Publications, Oxford.

26. Meredith, D. S. 1965. Violent spore release in Helminthosporium turcicum in Nebraska. Phytopathology 55:1099-1102.

27. Mundt, C. C. 1989. Modeling disease increase in host mixtures. Pages 150-181 in: Plant Disease Epidemiology, Vol. 2. Genetics, Resistance and Management. K. J. Leonard and W. E. Fry, eds. McGraw-Hill Publishing Co., New York.

28. Mundt, C. C., and Leonard, K. J. 1986. Analysis of factors affecting disease increase and spread in mixtures of immune and susceptible plants in computer-simulated epidemics. Phytopathology 76:832-840.

29. Mundt, C. C., and Leonard, K. J. 1986. Effect of host genotype unit area on development of focal epidemics of bean rust and common maize rust in mixtures of resistant and susceptible plants. Phytopathology 76:895900 .

30. Nelson, S. C., and Campbell, C. L. 1992. Incidence and patterns of association of pathogens in a leaf spot disease complex on white clover in the Piedmont region of North Carolina. Phytopathology 82:10131021.

31. Nelson, S. C., and Campbell, C. L. 1993. Disease progress, defoliation, and spatial pattern in multiple-pathogen disease complex on white clover. Phytopathology 83:419-429.

32. Newton, C. A. 1997. Cultivar mixtures in intensive agriculture. Pages 65-80 in: The Gene-for-Gene Relationship in Plant-Parasite Interactions. I. R. Crute, E. B. Holub, and J. J. Burdon, eds. CAB International, Wallingford, U.K.

33. Newton, M. R., Kinkle, L. L., and Leornard, K. J. 1997. Competition and density dependent fitness in coexisting foliar pathogens. Ecology 78:1774-1784

34. Ngugi, H. K. 1998. Epidemiology and management of sorghum anthracnose and leaf blight in Kenya. Ph.D. thesis. University of Reading, U.K.

35. Ngugi, H. K., Julian, A. M., King, S. B., and Peacocke, B. J. 2000. Epidemiology of sorghum anthracnose (Colletotrichum sublineolum) and leaf blight (Exserohilum turcicum) in Kenya. Plant Pathol. 49:129-140.

36. Nicholson, R. L., and Moraes, W. B. C. 1980. Survival of Colletotrichum graminicola: Importance of the spore matrix. Phytopathology 70:255261.

37. Niks, R. E., Ellis, P. R., and Parlevliet, J. E. 1993. Resistance to parasites. Pages 422-443 in: Plant Breeding: Principles and Prospects. M. D. Hayward, N. O. Bosemark, and I. Ramagosa, eds. Chapman and Hall, London.

38. Ntahimpera, N., Dillard, H. R., Cobb, A. C., and Seem, R. C. 1996. Anthracnose development in mixtures of resistant and susceptible dry bean cultivars. Phytopathology 86:668-673.

39. Odvody, G. N., and Hepperly, P. R. 1992. Foliar diseases of sorghum. Pages 167-177 in: Sorghum and Millet Diseases: A Second World Review. J. A. de Milliano, R. A. Frederiksen, and G. D. Bengstron, eds. International Crops Research Institute for the Semi-Arid Tropics, Patancheru, India.

40. Pande, S., Mughogho, L. K., Bandyopadhyay, R., and Karunakar, R. I. 1991. Variation in pathogenicity and cultural characteristics of sorghum isolates of Colletotrichum graminicola in India. Plant Dis. 75:778-783.

41. Pianka, E. R. 1983. Evolutionary Ecology. 3rd ed. Harper and Row, New York.

42. Powel, N. T. 1979. Internal synergisms among organisms inducing disease. Pages 113-133 in: Plant Disease: An Advanced Treatise. Vol. 4. J. G. Horshfall and E. B. Cowling, eds. Academic Press, New York.

43. Robinson, R. A. 1976. Plant Pathosystems. Springer-Verlag, New York.

44. Shaw, M. W., and Peters, J. C. 1994. The biological environment and pathogen population dynamics: Uncertainty, coexistence and competition. Pages 17-37 in: Ecology of Plant Pathogens. J. P. Blakeman and B. Williamson, eds. CAB International, Wallingford, U.K.

45. Sifuentes-Barrera, J. A., and Frederiksen, R. A. 1994. Evaluation of sorghum hybrid mixtures for controlling sorghum leaf blight. Plant Dis. 78:499-503

46. Steadman, O. J. 1980. Splash droplet and spore dispersal studies in field beans (Vicia faba L.). Agric. Meteorol. 21:111-127.

47. Stitcher, L., Mauch-Manui, B., and Métraux, J. P. 1997. Systemic acquired resistance. Annu. Rev. Phytopathol. 35:235-270.

48. Thurston, D. H. 1992. Sustainable Practices for Plant Disease Management in Traditional Farming Systems. Westview Press, Oxford. 
49. Tuleen, D. M., and Frederiksen, R. A. 1977. Characteristics of resistance to Exserohilum (Helminthosporium) turcicum in Sorghum bicolor. Plant Dis. Rep. 61:657-661.

50. Turechek, W. W., and Madden, L. V. 2000. Analysis of the association between the incidence of two spatially aggregated foliar diseases of strawberry. Phytopathology 90:157-170.

51. Van Wees, S. C. M., Pieterse, C. M. J., Trijssenaar, A., van Westende, Y. A. M., Hartog, F., and van Loon, L. C. 1997. Differential induction of systemic resistance in Arabidopsis by biocontrol bacteria. Mol. PlantMicrobe Interact. 10:716-724.
52. Weber, G. E. 1996. Modelling interactions between epidemics of Erysiphe graminis and Septoria nodorum on wheat. Z. Pflanzenkrankr. Pflanzenschutz 103:364-376.

53. Wolfe, M. S. 1985. The current status and prospects of multiline and variety mixtures for disease resistance. Annu. Rev. Phytopathol. 23: 251-273.

54. Wolfe, M. S. 2000. Crop strength through diversity. Nature 406:681-682.

55. Zhu, Y., Chen, H., Fan, J., Wang, Y., Li, Y., Chen, J., Fan, J., Yang, S., Hu, L., Leung, H., Mew, T. W., Teng, P. S., Wang, Z., and Mundt, C. 2000. Genetic diversity and disease control in rice. Nature 406:718-722. 